\title{
EXPLORANDO A INTERNACIONALIZAÇÃO DAS EMPRESAS BRASILEIRAS E SUA RELAÇÃO COM A INOVAÇÃO TECNOLÓGICA
}

\author{
Exploiting the link between internationalization \\ and technological innovation in brazilian \\ transnational companies
}

\author{
Ana Elisa Martins Pacheco de Castro ${ }^{1}$ \\ Crisomar Souza ${ }^{2}$ \\ Marcos Roberto Piscopo ${ }^{3}$ \\ Belmiro Nascimento João ${ }^{4}$
}

\begin{abstract}
Resumo
Este artigo estudou algumas empresas brasileiras com a finalidade de verificar a existência de alguma relação entre o grau de internacionalização e a prática da inovação tecnológica. A seleção das empresas estudadas envolveu o cruzamento das empresas mais internacionalizadas (Fundação Dom Cabral), com as empresas mais inovadoras (FINEP). A partir dessa amostra de empresas brasileiras, algumas em processo de internacionalização, foram analisados os dados de internacionalização e inovação e, posteriormente, realizaramse pequenas análises desses casos. Os resultados demonstraram que existe forte relação entre o grau de internacionalização e a prática da inovação tecnológica e também sugeriram que essa relação pode ser considerada como um determinante para a competitividade global das empresas analisadas. A referida relação apresentou-se válida para todas as empresas estudadas, mesmo havendo diferenças nas suas trajetórias de internacionalização e nos focos de inovação, pois algumas enfatizam a inovação em produto e outras enfatizam a inovação em processo. Foi ${ }^{1}$ Mestranda de Administração PUC-SP. E-mail: anaelisacastro@hotmail.com ${ }^{2}$ Mestrando de Administração PUC-SP. E-mail: crisomar@strategies.com.br ${ }^{3}$ Doutorando em Administração FEA/USP. Adjunct Lecturer no Management Departament da Bentley University. E-mail: mpiscopo@bentley.edu

4Professor Doutor, Titular do Programa de Pós-Graduação de Administração PUC/SP. E-mail: bjoao@pucsp.br
\end{abstract}


possível verificar que, a partir desta análise, pesquisas adicionais deveram ser conduzidas, posteriormente, no sentido de investigar o processo de internacionalização de cada uma dessas empresas. Espera-se, dessa forma, contribuir para os estudos de internacionalização de empresas brasileiras e sua relação com a inovação.

Palavras-chave: Inovação Tecnológica; Competitividade; Internacionalização.

\begin{abstract}
This paper has studied some Brazilian companies with the purpose of verifying the existence of any relationship between the degree of internationalization and the practice of technological innovation. The selection of the companies studied involved the intersection of the most internationalized firms according to the research carried out by the Fundação Dom Cabral with the most innovative firms as per FINEP. From this sample of Brazilian companies who are going international, we analyzed the data related to the internationalization and innovation. The findings showed that there is a relationship between the degree of internationalization and the practice of technological innovation. Moreover, results indicated that this relationship could be considered as a determinant of global competitiveness. We also identified that this relationship is valid for all companies analyzed, even though they have different internationalization trajectories and innovation foci.
\end{abstract}

Keywords: Technological Innovation; Competitiveness; Internationalization.

\title{
1 Introdução
}

Dentre os países em desenvolvimento, o Brasil é o terceiro principal exportador e atua no mercado externo com investimentos diretos da ordem de US\$28 bilhões (FINEP, 2006). Ao considerar as 100 principais empresas desafiantes globais em países emergentes, verificou-se que 17 dessas empresas são nacionais (BCG, 2008), em outras palavras, 17\% das empresas mais competitivas no contexto global são brasileiras, o que reserva papel de destaque para o País no cenário macroeconômico internacional. Entretanto, a maneira como essas empresas concorrem no exterior e o grau de diferenciação dos produtos brasileiros apontam para a eficiência da gestão de inovação tecnológica das referidas empresas frente às suas concorrentes nos mercados estrangeiros locais. Nesse sentido, a inovação é considerada como um grande diferencial competitivo das empresas nos estudos internacionais, mas o seu conceito é bastante abrangente e envolve não somente o desenvolvimento de novos produtos e processos, mas também inovações organizacionais e inovações de marketing (OCDE, 2005). Assim, o entendimento da inovação abrange, além das atividades relacionadas à pesquisa $\mathrm{e}$ desenvolvimento (P\&D), a habilidade de criar valor para os clientes da organização, o que, conseqüentemente, eleva a sua competitividade.

Pesquisa realizada pelo IBGE (2003) identificou números que merecem atenção tanto dos acadêmicos como dos praticantes, dentre os quais se destacam: (i) 33\% das empresas brasileiras inovam; (ii) a tecnologia participa com 1,7\% das exportações na balança comercial e (iii) as empresas inovadoras brasileiras são responsáveis por 25,9\% do faturamento industrial 
e por 13,2\% do emprego gerado. Tais dados demonstram a relevância da inovação para a competitividade no mercado brasileiro e reforçam a necessidade de intensificar a sua prática, especialmente para empresas que competem em âmbito mundial.

Por meio de um estudo exploratório de abordagem qualitativa envolvendo múltiplos casos, objetiva-se verificar a relação existente entre o grau de internacionalização e a capacidade de inovação tecnológica das empresas brasileiras. Dessa forma, espera-se compreender como a prática da inovação suporta a expansão internacional das empresas brasileiras viabilizando a sustentação de vantagens competitivas e a identificação de oportunidades para novos negócios. Para este fim, o trabalho foi estruturado em cinco partes. Esta parte apresenta o tema e contexto em que se situa. A segunda parte contempla a revisão teórica, que abrange especificamente dois aspectos: a inovação propriamente dita, ressaltando seus tipos, alguns fatores que favorecem o seu surgimento e sua importância para a conquista e sustentação do diferencial competitivo das empresas e a internacionalização, evidenciando os fatores motivadores da internacionalização, os modos de entrada e as estratégias envolvidas na seleção dos mercados alvo. Na terceira parte demonstram-se os procedimentos metodológicos empregados neste estudo. A quarta parte refere-se ao estudo dos casos e constitui-se da apresentação e da análise dos casos selecionados. Na quinta parte apresentam-se as considerações finais, mais especificamente, as conclusões, as limitações deste trabalho e sugestões para continuidade do presente esforço.

\section{Referencial teórico}

\subsection{Inovação nas empresas brasileiras}

Várias são as definições de inovação tecnológicas (CLARK e WHEELWRIGHT, 1992; DOSI, 1988; VAN DE VEN et al., 1989), entretanto, para orientação deste artigo, será adotada a definição apresentada pelo Manual de Oslo (OCDE, 2005), principal fonte internacional de diretrizes para coleta e uso de dados sobre atividades inovadoras. O referido manual considera como inovação tecnológica "todas as mudanças que envolvem um grau significativo de novidade para a empresa" e se concentra em produtos e processos aprimorados. Mesmo considerando que as inovações organizacionais são responsáveis por melhorias significativas nas empresas, o manual em questão opta por não se aprofundar no desenvolvimento dessa modalidade de inovação. Apesar da relevância do assunto inovação organizacional, para o processo de internacionalização de empresas, o recorte desta pesquisa se limita à compreensão do processo de inovação apenas no que tange aos aspectos tecnológicos relativos aos produtos e processos que geram valor para os clientes internos e externos. Ainda segundo o Manual de Olso (OCDE, 2005), a gama de oportunidades para a inovação é influenciada por fatores externos, como o ambiente que cerca as instituições, os sistemas jurídicos e o contexto macroeconômico.

Dificuldades burocráticas, econômicas e políticas que retardam a inovação e dificultam o ambiente inovador são comumente observadas em países em desenvolvimento (BUSINESSWEEK, 2008; KHANNA, PALEPU e SINHÁ, 2005), que carecem de investimento não somente em infra-estrutura, mas também no estabelecimento de um sistema de ensino básico, acesso a instituições financeiras que incentivem o desenvolvimento, diminuição da burocracia e manutenção de sistema legal eficiente (OCDE, 2005). A resolução de problemas dessa natureza favorece a indústria nacional, preserva o mercado interno frente a entrantes estrangeiros e aumenta a competitividade de produtos no mercado externo. Sobre as economias 
emergentes, Prahalad (2005, p. 41) afirma que "a oportunidade de mercado na base da pirâmide não pode ser suprida por versões obsoletas de soluções tecnológicas tradicionais partindo de mercados desenvolvidos". A afirmação reitera a importância da inovação para a manutenção da atual competitividade da organização nos mercados em que ela já atua e aponta a absoluta necessidade da inovação para servir novos mercados, especialmente aqueles situados na base da pirâmide.

A inovação tecnológica não precisa ser necessariamente uma novidade para o mercado, ela pode ser considerada uma inovação apenas para a empresa. Entende-se, portanto, que a mudança aconteceu não no produto, mas sim no seu processo de produção. Essas modificações estão normalmente relacionadas à redução de custos e à melhoria da eficiência produtiva. Clark e Wheelwright (1992) tipificam as inovações de acordo com o grau de modificação no produto ou processo como:

- projetos de desenvolvimento avançado: caracterizados pela criação de novos conhecimentos;

- alianças ou parcerias: a organização pode procurar parcerias para desenvolver pesquisas avançadas e buscar um novo conceito de produto;

- incrementais ou derivados: produtos e processos derivados, híbridos ou melhorados que utilizam pouco investimento e aproveitam os recursos já existentes - sustentação;

- plataformas ou novas gerações: geram grandes mudanças tanto no produto como no processo para o surgimento das "famílias". Representam projetos de longo prazo, que suportarão próximas gerações dos produtos/processos e os ligarão com as gerações subseqüentes;

- radicais ou inovadores: são aqueles que envolvem grandes modificações, estabelecendo novos conceitos de produtos e processos.

Os tipos "pesquisa e desenvolvimento avançado" e "alianças e parcerias de projeto", apesar de estarem alinhados à estratégia, ocorrem fora da empresa e não estão sujeitos às variáveis de mudança de produto e processo. No caso das empresas brasileiras em processo de internacionalização, esses dois tipos de inovação representam grandes desafios a serem superados à medida que as referidas empresas elevarem sua exposição nos mercados estrangeiros. Portanto, surge a necessidade de desenvolver novos conhecimentos tecnológicos e estabelecer parcerias que viabilizem o acesso aos recursos necessários para a criação de novos conceitos de produtos. Essas ações devem permitir que a empresa usufrua dos benefícios do desenvolvimento tecnológico geograficamente disperso e, ao mesmo tempo, possibilitem uma atuação mais próxima dos mercados regionais em que ela compete.

Arruda, Vermuld e Hollanda (2006) verificaram que, em dados fornecidos pelo IBGE sobre inovação tecnológica, em 2003, a maior parte das empresas brasileiras inova em processo. Entretanto, quando o foco é o mercado interno, a inovação em produto é maior. Segundo esses autores, isso acontece porque a maior parte das inovações de processo se deve à compra de máquinas e equipamentos, ou seja, à atualização do parque industrial. Essa verificação coloca o Brasil em situação de desvantagem perante outros países, uma vez que a diferenciação tecnológica de produtos é deficiente, como mostra o ranking de competitividade do IMD (BUSINESSWEEK, 2008), que posiciona o Brasil na 43a posição. A inovação de produto ocorre mais facilmente em empresas de teor tecnológico, e a inovação de processo está mais comumente relacionada a produtos comoditizados.

A chave não está em descobrir qual tipo de inovação (produto ou processo) é mais importante, mas em identificar como a inovação de produto e de processo contribuem para a conquista e a sustentação da vantagem competitiva. Em mercados cujo ciclo de vida do produto é reduzido, a inovação de produto é essencial, pois assegura a sobrevivência da empresa por meio do atendimento das necessidades emergentes dos clientes atuais e também 
daquelas provenientes dos potenciais clientes. Dessa forma, a inovação de produto suporta estrategicamente as empresas cuja competitividade baseia-se no provimento constante de novas ofertas para clientes que desejam produtos caracterizados pelo estado da arte. Portanto, a inovação de produto apresenta consistência com a estratégia de liderança em produto sugerida por Treacy e Wieserma (1995). No caso da inovação de processo, o foco está em executar as mesmas atividades que os concorrentes executam, porém com menor custo e prazo mais reduzido do que eles. Adicionalmente, a inovação de processo também pode conferir relativa vantagem para a organização, à medida ela desempenha determinada atividade que os seus concorrentes não conseguem imitar no curto prazo. Assim, a inovação de processo está alinhada com a estratégia denominada excelência operacional, segundo as disciplinas dos líderes de mercado propostas por Treacy e Wieserma (1995).

Teigland, Fey e Birkinshaw (2000) reiteram que as empresas devem parte de seu sucesso à sua capacidade de criar vantagem competitiva por meio da introdução de inovações tecnológicas. Cada vez mais se observa a busca pelo estabelecimento de padrões tecnológicos que possam conferir à organização um diferencial competitivo de longo prazo. Apesar de ser extremamente difícil alcançar a referida posição competitiva, o desenvolvimento tecnológico deve ser uma prioridade para as empresas em processo de internacionalização. Certamente algumas tecnologias são aplicadas globalmente e outras somente possuem aplicações regionais, fato que requer que a empresa desenvolva as habilidades para gerenciar suas tecnologias com a finalidade de apoiar sua estratégia de internacionalização. Para tanto, é necessário que a estratégia tecnológica internacional esteja alinhada com a estratégia competitiva internacional para que a organização consiga obter os benefícios resultantes dessa combinação estratégica.

\subsection{Internacionalização de empresas brasileiras}

\subsubsection{Agentes motivadores}

O modo como as empresas organizam suas atividades de internacionalização é alvo de estudos desde as décadas de 1960 e 1970 (CYERT e MARCH, 1963; VERNON, 1966; JOHANSON e VAHLNE, 1977; BILKEY, 1978; JOHANSON e MATTSSON, 1988, 1990). Apesar dos diferentes focos e abordagens, verificou-se que a motivação na busca por mercados estrangeiros acontece por razões como: necessidade de crescimento, exploração de economia de escala, busca de eficiência, desejo de aproveitar tecnologia já desenvolvida, busca de diferentes tipos de recursos (naturais, como exploração, facilidade de mão-de-obra ou acesso a capital de menor custo), busca do conhecimento especializado via aquisições e até para redução de risco, uma vez que a diversificação geográfica diminui a dependência da empresa em relação a um único mercado (PORTER, 1986; DUNNING, 2001; YIP, 1989, 1996). Além desses motivos, a análise dos "impulsores governamentais e competitivos" (YIP, 1989, 1996) ambiente macroeconômico e político, tais como, economia estabilizada, medidas governamentais favoráveis para acesso a captação, incentivos fiscais, entre outros, podem fortalecer a estratégia para a expansão internacional das empresas. Segundo Porter (1986, p. 260), "uma indústria tornase global basicamente porque existem vantagens econômicas (entre outras) em uma empresa competir de maneira coordenada em muitos mercados nacionais".

A diversificação de mercados embute benefícios econômicos e de aprendizado organizacional, uma vez que, para adaptar-se a novos ambientes, é necessário reestruturar-se e adequar seus produtos e serviços às necessidades locais (HITT, IRELAND e HOSKISSON, 2002). No caso de países em desenvolvimento, as empresas que estabelecem atividades comerciais com países desenvolvidos, em mercados considerados maduros, têm a oportunidade de aprender 
com eles e aumentar o seu potencial de inovação. Uma vez definidas as razões que levam a empresa a internacionalizar-se, cabe ao gestor decidir o modo de entrada nesses mercados, como será visto a seguir.

\subsubsection{Modos de entrada}

Existem elementos da estratégia de entrada em mercados internacionais que devem ser observar à luz de sua definição, como, por exemplo: (i) a escolha do produto e do mercado alvo; (ii) o estabelecimento de objetivos e metas; (iii) a escolha do modo de entrada: exportação, acordos contratuais ou investimento; (iv) o desenho do plano de marketing (preço, promoção, distribuição); e (v) o sistema de controle, ou seja, o monitoramento do desempenho das operações no mercado alvo e a revisão da estratégia de entrada. Esse modelo, apesar de ser apresentado de forma seqüencial, é algo dinâmico e exige contínuas revisões no decorrer do processo (ROOT, 1987). Neste trabalho será abordada apenas a escolha dos modos de entrada, em razão de estarem diretamente relacionados ao nível de comprometimento da empresa com o país de destino. Dentre os modos de entrada mais freqüentes, encontra-se a exportação (direta e indireta), o licenciamento, as alianças estratégicas, as aquisições e, por fim, o estabelecimento em mercado local por meio de nova subsidiária de propriedade da matriz (ROOT, 1987). Cada uma dessas estratégias de entrada possui pontos fortes e fracos como será demonstrado a seguir.

A exportação é o modo menos arriscado para entrada em novos mercados, uma vez que envolve menos investimento de capital e esforços reduzidos de coordenação e controle. Suas atividades podem acontecer diretamente, por meio de escritório de vendas local, ou indiretamente, com a presença de intermediários. Uma grande desvantagem relacionada a este modo de entrada é o aumento de preço do produto final devido à adição de somas de transporte, tarifas alfandegárias, custos aduaneiros e a própria margem de lucro do importador. Contudo, a exportação geralmente é adotada por empresas em estágio inicial de seu processo de internacionalização. Dessa forma, a empresa pode testar e conhecer diversos mercados estrangeiros locais sem o comprometimento com a realização de investimentos significativos relativos ao estabelecimento de unidades próprias de operação.

O licenciamento permite que outra empresa adquira o direito de uso de marca, de produtos, de patentes, de matérias-primas, de processos de produção em troca do pagamento de royalties. O licenciado assume os riscos dos investimentos para produzir, comercializar e distribuir o produto e, por isso, é considerada a forma mais barata para iniciar o processo de comercialização externa. Entre as desvantagens do modelo está o pouco controle que a empresa tem sobre a produção e comercialização dos produtos (HITT, IRELAND e HOSKISSON, 2002). Esse controle reduzido pode representar um risco caso o licenciado não apresente o nível de comprometimento desejado pela empresa multinacional. Adicionalmente, o licenciado pode desempenhar suas atividades de forma inadequada e proporcionar prejuízos de imagem para a corporação. Considerando que a construção da imagem internacional da marca é um dos principais desafios a serem superados pelas multinacionais provenientes de países emergentes, a redução dos custos de operações internacionais no curto prazo pode comprometer o processo de expansão global no longo prazo.

As alianças estratégicas tornaram-se bastante populares a partir da década de noventa (WEBSTER, 1992) e sua principal vantagem é a divisão dos riscos e dos recursos para entrar em mercados internacionais. A parceria proporciona o desenvolvimento das competências necessárias para atender às necessidades dos mercados estrangeiros locais, visto que a associação com uma empresa situada nesses mercados pode viabilizar o acesso a matérias-primas especiais, 
mão-de-obra especializada e canais de distribuição não convencionais. A principal dificuldade do estabelecimento de alianças está na administração de interesses concorrentes e, por esse motivo, nem todas as parcerias são bem-sucedidas. Portanto, a identificação do parceiro ideal para o processo de expansão internacional é um fator-chave de sucesso para a formação de alianças estratégicas. Hitt, Ireland e Hoskisson (2002) apontam que as alianças podem ser classificadas em três categorias: joint ventures, alianças estratégicas com troca de ativos e alianças estratégicas sem troca de ativos.

As aquisições proporcionam rápido acesso ao mercado local, mas seu custo é bastante elevado e envolve, na maior parte das vezes, negociações bastante delicadas entre as partes (HITT, IRELAND e HOSKISSON, 2002). Outra questão bastante relevante é a fusão da cultura das duas empresas que, quando não-gerenciada, pode acarretar conseqüências desastrosas para a empresa adquirente. Apesar do elevado custo, a aquisição proporciona o benefício da economia de tempo, uma vez que o alvo se trata de uma organização devidamente constituída e que se encontra em operação. Conseqüentemente, a aquisição pode viabilizar a otimização de oportunidades emergentes em determinadas regiões devido à agilidade conferida à corporação multinacional para compreender os mercados locais e enfrentar os principais concorrentes regionais.

O estabelecimento de subsidiária ou greenfield venture, apesar de ser um processo mais arriscado, mais complexo e potencialmente mais dispendioso, garante à empresa maior controle sobre as atividades. Dessa forma, a empresa multinacional reduz sua dependência em relação a outras organizações locais. Essa modalidade de entrada refere-se ao grau mais elevado de comprometimento com operações internacionais. Apesar dos elevados custos e riscos inerentes a esse tipo de estratégia, destaca-se a possibilidade de auferir lucros atrativos para a corporação, fortalecer a imagem da marca em internacionalmente e reduzir a dependência da corporação relativamente ao mercado doméstico do seu país de origem.

\subsubsection{Seleção de mercados: da abordagem econômica à comportamental}

A estratégia para seleção de mercados também é alvo de estudos desde a década de 1960, destacando-se duas abordagens: uma que orienta as ações pela análise do ambiente econômico (CYERT e MARCH, 1963; VERNON, 1966; DUNNING, 2001) e outra que considera o comportamento do ambiente de negócios da empresa, também chamado de comportamental (JOHANSON e VAHLNE, 1977; BILKEY, 1978; JOHANSON e MATTSSON,1988, 1990). A teoria eclética da internacionalização procura explicar, por meio de motivações econômicas, a decisão de produzir ou não em um mercado externo (DUNNING, 1980, 1988). O autor dessa teoria condiciona algumas variáveis estruturais e conjunturais, como as características do país e da indústria com variáveis operacionais e estratégias específicas da firma. Para tanto, utiliza-se da análise de três elementos: ownership, location e internalization (OLI).

O primeiro elemento fala sobre as vantagens de propriedade relacionadas ao local (ownership). Essa variável envolve capacidades próprias desenvolvidas pela organização que permitem que ela se posicione relativamente melhor no mercado internacional se comparadas a outros produtores locais ou demais produtores estrangeiros. Entre alguns exemplos de vantagem de propriedade, destacam-se o conhecimento e as habilidades técnicas, a oportunidade de investimento dependendo do tamanho do mercado local, a diversidade de produto e maior produtividade (mais venda por empregado). O segundo elemento, locação (location), indica que uma empresa localiza suas atividades para ganhar acesso à mão-de-obra, capital, materiais e outros insumos baratos ou para vender próximos de seus clientes e evitar os custos de transportes e tarifas. Por último, Dunning (1980, 1988) evidencia a internalização (internalization), a qual 
a empresa analisa as vantagens econômicas entre a exportação e a produção local. Em outras palavras, se os custos de incorporação e organização produtiva forem menores do que os custos de transação associados à transferência dessas capacidades a um produtor local, a firma investirá na produção nesse mercado. Isso explica por que a empresa escolhe explorar suas vantagens por meio de propriedade direta, ao invés de fazer joint venture, ou oferecer licença, ou conceder franquia, ou, ainda, simplesmente assinar acordos de vendas de exportação com empresas no exterior.

Segundo Dunning (2003), o paradigma eclético (OLI) permite analisar as tendências das firmas em promover e controlar atividades de valor agregado para além das fronteiras nacionais. A extensão e o padrão da produção da firma no exterior, financiada por IED, serão determinados pela força e interação entre três conjuntos de variáveis: recursos e capacidades específicos e únicos $(\mathrm{O})$ da firma potencialmente investidora; locações alternativas atraentes (L) em países e regiões que ofereçam vantagens e estruturas para criar recursos e capacidades; e a extensão pelas quais as firmas internalizam (I) (DUNNING, 1977, 1980). As vantagens de propriedade de uma firma podem ser de natureza estrutural, derivada da posse de ativos intangíveis (patentes, marcas, capacidades tecnológicas e de management, habilidade para a diferenciação de produtos) e/ou de natureza transacional, derivada da capacidade de hierarquia, decorrente do common governance de atividades diversas que resultam da própria característica multinacional da empresa. A decisão de produzir no exterior, dado um determinado contexto legal e econômico, ao invés de licenciar ou exportar, está fortemente relacionada à natureza dos seus ativos intangíveis (conhecimentos tácitos), especialmente os que resultam das práticas tecnológicas, de management, ou de comercialização da firma.

Quando a firma internaliza, ela decide produzir para obter economias de escala ou para reduzir custos de transação e coordenação, resultantes da incerteza e da existência de externalidades. Da mesma forma que os ativos intangíveis, resultantes do conhecimento implícito, a existência de vantagens de localização também favorece a produção local ao invés da exportação ou do licenciamento. Segundo a teoria eclética, uma firma vai continuar o seu processo de internacionalização, passando a produzir no mercado de destino, se possuir vantagens proprietárias que torne necessário ou vantajoso internalizar mercados.

Uma segunda abordagem para a seleção de mercados trata da análise do ambiente de negócios da empresa. A teoria diz que a transformação da empresa doméstica em multinacional depende das características da empresa, do setor ou do ambiente macroeconômico e legal, normalmente implica como parte de um processo de penetração gradual no mercado externo (JOHANSON e VAHLNE, 1977; JOHANSON e MATTSSON, 1988, 1990). Essa abordagem que focaliza a análise do ambiente de negócios é chamada comportamental, pois prevê o processo de internacionalização como algo gradual, que envolve conhecimento do ambiente. Para a linha comportamental, a análise do ambiente fundamenta as decisões estratégicas da empresa. A abordagem indica em que medida o conhecimento sobre este mercado aumenta, ou seja, que a empresa incrementa o comprometimento de suas atividades comerciais locais. Dessa forma, as empresas iniciam lentamente o seu processo de internacionalização e, à medida que o conhecimento sobre o mercado local cresce, aumenta também a sua confiança no investimento de recursos naquele país, o que reflete no comprometimento de suas atividades comerciais locais. Dessa forma, em um primeiro momento, a empresa opta por iniciar suas atividades via exportação, o que se deve a um custo relativamente mais baixo nas operações e menor exposição aos riscos. À medida que a empresa aumenta o seu conhecimento local sobre aspectos políticos, econômicos, concorrencial, cultural, entre outros, a organização parte para o estabelecimento de subsidiária própria (JOHANSON e VAHLNE, 1977; JOHANSON e MATTSSON, 1988, 1990). 
Johanson e Vahlne (1977) observaram, ainda, que a escolha dos países alvo obedece a certa lógica de proximidade geográfica, cultural, econômica, conhecida como "distância psíquica". Essas diferenças ou distâncias geram incertezas sobre os resultados das transações e só podem ser diminuídas pelo conhecimento da outra cultura. Reduzindo a distância psíquica, diminuem as incertezas iniciais e, dessa maneira, pode ser aumentado o comprometimento de recursos. Para a escola de Uppsala, o processo de internacionalização possui duas características básicas: o conhecimento do mercado e o comprometimento de recursos. Para Cavusgil (1980), o padrão gradual de internacionalização decorre das maiores incertezas, dos custos de informação mais elevados e da falta de conhecimento empírico em atividades de marketing no exterior. A exportação teria as características de uma inovação para a empresa, pois há, nessa atividade, uma grande incerteza, que só pode ser reduzida gradualmente por meio do conhecimento, fruto da própria experiência exportadora. Na medida em que a firma reduz a incerteza, com a experiência e o conhecimento adquirido na atividade, pode comprometer mais recursos e avançar no processo de internacionalização.

\section{Metodologia}

O presente artigo caracteriza-se como uma pesquisa de caráter exploratório. O método exploratório é recomendado para situações em que o conhecimento sobre o tema em análise ainda é reduzido ou demanda novos estudos (SELLTIZ et al., 1974). Goode e Hatt (1979) ressaltam a possibilidade do emprego do método exploratório em trabalhos de orientação qualitativa que visam à obtenção de informações que elucidem um objeto de estudo com a finalidade de construir variáveis ou elaborar hipóteses que possam ser testadas em outros estudos posteriores. Tais procedimentos podem ser utilizados nas situações em que a questão de pesquisa envolva aspectos relativos a "como" ou "por que" determinados eventos ocorrem e o pesquisador não detém controle sobre eles (YIN, 1994).

Portanto, este trabalho está baseado em uma pesquisa exploratória, que busca levantar informações sobre um determinado objeto, delimitando, assim, um campo do trabalho que servirá como subsídio para a pesquisa explicativa posterior (SEVERINO, 2008). Mais especificamente, a presente pesquisa envolve a análise de nove casos com o propósito de melhor compreender a relação existente entre o grau internacionalização e a prática da inovação tecnológica nas empresas multinacionais brasileiras.

Considerando que a seleção dos casos é um ponto de relevância para a elaboração de teorias a partir de estudos de casos (EISENHARDT, 1989), os autores procuraram identificar quais empresas poderiam ser representativas para a questão de pesquisa deste trabalho. $\mathrm{O}$ critério adotado para a referida seleção envolveu o cruzamento da relação das empresas mais inovadoras (FINEP, 2006) com a listagem das empresas mais internacionalizadas, segundo estudos da Fundação Dom Cabral (ALMEIDA e CRETOIU, 2008). Observa-se que os dados utilizados neste artigo são de origem secundária, contudo, os autores acreditam que tais dados são suficientes para o presente trabalho, uma vez que este se caracteriza como um estudo exploratório, conduzido inicialmente para aumentar a familiaridade dos autores com os temas de internacionalização e inovação tecnológica. Dessa forma, os resultados obtidos ao final desta pesquisa orientarão novos esforços de investigação que serão conduzidos pelos autores.

\section{Estudos de caso}

A análise dos estudos de caso objetiva averiguar se o potencial inovador da empresa impacta na sua internacionalização e qual é o grau de envolvimento de cada empresa com os

Rev. Adm. UFSM, Santa Maria, v. 1, n. 3, p. 241-262, set./dez. 2008 
mercados externos. Verificando-se os dados da FINEP (2006) e da FDC (ALMEIDA e CRETOIU, 2008), nota-se que das 40 empresas classificadas como inovadoras, 38 são brasileiras e duas são de origem alemã. Entre as 38 empresas de origem nacional, 11 atuam apenas no mercado local e 27 possuem algum envolvimento com mercados externos, o que demonstra a existência de forte relação entre o potencial inovador e a procura por novos mercados estrangeiros.

Das empresas que possuem envolvimento externo, 12 ainda estão em estágio inicial de internacionalização e participam do cenário internacional apenas por meio de exportações (JOHANSON e VAHLNE, 1977). Isso pode ocorrer por fatores como porte da empresa ou falta de maturidade das inovações no mercado local. As outras 15 empresas do grupo apresentam maior grau de comprometimento com outros países e estabeleceram atividades comerciais via subsidiárias próprias. Verifica-se que se tratam de empresas de porte maior, o que sugere maior experiência competitiva e conhecimento local para explorar economicamente potencialidades no exterior (CYERT e MARCH, 1963; VERNON, 1966; DUNNING, 2001).

Para entender se havia maior concentração de potencial inovador em algum setor, as empresas foram estudadas de acordo com sua área de atuação e verificou-se que elas estão distribuídas em nove setores: (i) bens de consumo; (ii) auto-indústria; (iii) farmacêutica e saúde; (iv) óleo, química e petroquímica; (v) construção civil e material de construção; (vi) eletroeletrônico; (vii) agropecuária; (viii) metalurgia e (ix) tecnologia. O setor com mais representantes inovadores é o de bens de consumo, e este fato pode estar relacionado com a necessidade de um menor período para desenvolvimento de produtos deste segmento. Em seguida, com igual número de representantes, estão a auto-indústria, a metalurgia e a tecnologia. Com exceção do setor de tecnologia, todas as demais empresas estão bastante voltadas à inovação de processo, o que sugere um forte apelo pela eficiência e pela redução de custos. Em um terceiro nível, encontram-se a farmacêutica e saúde e a óleo, química e petroquímica, as quais apresentam inovações bastante impactantes para o mercado; entretanto, seu ciclo de desenvolvimento de produto é bastante longo, existindo forte dependência de P\&D. Por último, com menor número de representantes, encontram-se: eletro-eletrônicos, construção e material de construção e agropecuária.

Para verificar se o potencial inovador das empresas impactava no seu grau de envolvimento com outros países, procurou-se a aderência entre os dados fornecidos pela FINEP (2006) sobre as empresas inovadoras e os obtidos por Almeida e Cretoiu (2008), que lista as empresas brasileiras mais internacionalizadas. Após cada uma delas foi relacionada por tipo de inovação tecnológica (produto ou processo) que desempenha. Dessa forma, obteve-se uma lista de nove empresas. Ao se analisar esses dados, observou-se que a maior parte das empresas mais inovadoras e internacionalizadas está concentrada no setor de auto-indústria (quatro representantes) e suas inovações acontecem em produto, o que sugere o forte compromisso dessas empresas com o atendimento das necessidades dos consumidores finais e empresas que participam da cadeia de valor desse setor. Em seguida, com dois representantes, está o setor de petróleo, química e petroquímica. Esses setores, tradicionalmente de capital intensivo, investem grandes somas em P\&D. Suas inovações estão voltadas ao processo. Os setores de metalurgia, material de construção e bens de consumo empataram, com apenas um representante cada, e todos focam seus esforços na inovação de produtos, o que demonstra a necessidade de criação de novas ofertas para os mercados consumidores e industriais, com o propósito de assegurar a fidelidade dos clientes sensíveis aos produtos que representam o estado da arte. 


\section{1 Petrobras}

A Petrobras é uma empresa do setor de energia que tem suas atividades concentradas nas áreas de petróleo e gás. Sua inovação tecnológica está mais voltada ao aumento da eficiência de seus processos, o que pode ser constatado por meio do diferencial competitivo estabelecido na prospecção e exploração de petróleo em águas profundas. Em 1972, a Petrobras deu início ao seu processo de internacionalização e, atualmente, está presente em 24 países, os quais, em 2006, foram responsáveis por quase $10 \%$ de seu faturamento.

Considerando-se que o setor de óleo e gás é um setor global, no qual se verifica a presença de empresas de porte extremamente elevado, que competem especialmente na prospecção e exploração dessas commodities, a inovação de processo representa um ponto forte dessa empresa e contribui para o seu processo de internacionalização. Mesmo descobrindo novas reservas, as quais fizeram da empresa a terceira maior companhia das Américas em valor de mercado, o acesso às camadas profundas de óleo e gás depende do avanço tecnológico da organização, com o propósito de viabilizar a extração e prosseguir com as atividades downstream que agregam valor aos seus produtos, que são comercializados em nível doméstico e internacional.

\subsection{Marcopolo}

A Marcopolo é uma das maiores fabricantes de carrocerias de ônibus do mundo e atua no setor de auto-indústria. A empresa iniciou seu processo de internacionalização, em 1990, e hoje está presente em cinco países, os quais, em 2006, foram responsáveis por mais de 40\% do faturamento da empresa.

A estratégia de internacionalização da Marcopolo não está ligada apenas à necessidade de crescimento e à preservação de sua tecnologia para montagem e fabricação de componentes internos para ônibus, mas também à adaptação de seus produtos aos mercados locais dos países em que a empresa compete. A preocupação com aspectos relacionados à adaptação e preservação de tecnologia própria reflete a importância que a empresa atribui à inovação de produtos para atender à demanda existente. Adicionalmente, a organização faz uso da inovação para criar novas oportunidades de negócios internacionais, como, por exemplo, assessórios para a indústria automotiva, construção civil e agrícola. Essa orientação inovadora da empresa tem se mostrado uma ótima estratégia de crescimento para o mercado doméstico e também para a expansão internacional.

\subsection{Sabó}

A Sabó é uma empresa do setor de auto-indústria na área de autopeças e sua capacidade inovadora em processos de vedação de peças de automóvel por meio de plasma, um gás ionizado, permitiu o desenvolvimento de produtos mais econômicos e ambientalmente corretos. Em 2006, cerca de 50\% do faturamento da empresa vieram de mercados estrangeiros.

A empresa iniciou seu processo de internacionalização em 1975, está presente em 10 países, e suas subsidiárias concentram-se fundamentalmente na Europa e nos Estados Unidos, considerados como pólos tecnológicos da indústria automobilística. Seu comprometimento com as operações internacionais pode ser constatado pelo elevado número de empregados que atuam fora do Brasil, aproximadamente $37 \%$.

A presença da Sabó em mercados como o europeu permite que ela identifique as tendências tecnológicas e faz com que a empresa tenha maior agilidade para se adaptar e atender 
às necessidades de seu público. A proximidade das subsidiárias da Sabó de seus clientes do setor automotivo proporciona também um ambiente rico para o surgimento de novos produtos e tecnologias. A empresa cria um ambiente tecnológico favorável ao aprendizado, viabilizado pelas constantes adaptações de produto, que são fundamentais para atender à exigente e competitiva indústria automobilística.

Portanto, observa-se a grande importância da inovação tecnológica para a Sabó, visto que seus principais clientes são as empresas montadoras de automóveis e, conseqüentemente, os distribuidores de autopeças. Em razão da elevada taxa de inovação no setor automotivo, especialmente no caso dos componentes operacionais do veículo, a Sabó estabelece forte posição competitiva como provedora de produtos de qualidade e segurança para os usuários.

\subsection{WEG}

A WEG é a maior fabricante latino-americana de motores elétricos e uma das maiores empresas desse segmento no mundo. Atua no setor metal-mecânico e concentra suas atividades nas áreas de comando e proteção; variação de velocidade; automação de processos industriais; geração e distribuição de energia e tintas e vernizes industriais. As inovações em seus produtos estão voltadas ao desenvolvimento e aperfeiçoamento de sua linha de motores, que é considerada a mais diversificada no mundo.

A empresa iniciou seu processo de internacionalização em 1991 e está presente em diversos países por meio de escritórios de vendas e representação, possuindo unidades fabris em Portugal, na Argentina, no México e na China. No ano de 2006, seu faturamento foi de US $\$ 3,527$ bilhões, sendo que US\$1,41 bilhão, cerca de $40 \%$ da receita, advêm de sua ação no mercado externo. A empresa possui cerca de 14.000 funcionários no Brasil e 4.000 no exterior.

Seus clientes estão concentrados na área industrial, segmento bastante sensível à redução de custos. Essa característica de seus clientes faz com que a WEG priorize esforços no aperfeiçoamento de motores elétricos com maior desempenho, como forma de garantir a economia de custos do produto final de seus clientes. As atividades da WEG no exterior focam a evolução tecnológica de qualidade e competitividade nos custos, o que mostra a orientação da empresa em direção à inovação de seus produtos e processos.

\subsection{Embraer}

Empresa do setor de auto-indústria na área de aeronáutica, a Embraer é considerada uma empresa de base tecnológica que inova em produto. Fabrica jatos cuja capacidade varia de 30 a 120 assentos, para atendimento das demandas específicas dos seus clientes. A organização também inovou no uso de ferramentas de trabalho e no processo de juntar times de parceiros mundiais para desenvolver produtos. Essa arquitetura aberta de inovação viabiliza o contato direto dos seus parceiros globalmente dispersos com seus clientes internacionais visando à criação das condições que permitam o desenvolvimento de produtos que entreguem valor superior aos seus clientes.

O processo de internacionalização da Embraer teve início em 1979. Com sede em São José dos Campos, a empresa está presente em seis países e, em 2006, obteve um faturamento de US $\$ 8,342$ bilhões, sendo que US\$8 bilhões resultaram de vendas internacionais. Relativamente à distribuição da sua força de trabalho, observa-se que, aproximadamente, $12 \%$ encontram-se globalmente dispersas, fato que demonstra a exposição e o comprometimento da organização com os mercados estrangeiros. 
A Embraer é um caso muito especial para esta pesquisa, pois se trata de uma empresa muito inovadora e extremamente internacionalizada no que se refere à elevada dependência das vendas oriundas de mercados estrangeiros. A forte orientação para a inovação contribui significativamente para a internacionalização da empresa, o que pode ser constatado a partir da utilização da arquitetura aberta, que proporciona grande satisfação para os clientes e ótimos resultados econômicos para a organização.

\subsection{Tigre}

A Tigre é uma empresa do setor de indústria de material de construção e produz tubos, conexões e acessórios em PVC. A empresa é líder na América Latina no seu segmento e se destaca pelo pioneirismo, inovação e qualidade. Como inovadora em produto, oferece soluções completas nas áreas em que atua e, com isso, a empresa procura oferecer uma linha extensa de produtos para a construção civil.

A empresa iniciou seu processo de internacionalização em 1977, estabelecendo sua primeira subsidiária no Paraguai. Atualmente conta com 18 plantas industriais em nove países e mantém relações comerciais, via exportação, com outros 35. Em 2006, a Tigre obteve um faturamento de US\$1,7 bilhão, dos quais US\$425 milhões foram resultados obtidos no exterior. Observa-se que 15,73\% de sua força de trabalho encontram-se globalmente dispersas, ratificando sua elevada exposição internacional.

A atividade inovadora da empresa acelerou-se há alguns anos, em função da decisão estratégica de adoção de um novo conceito para a comercialização dos produtos, ou seja, oferecer soluções completas nas áreas em que atua. Somente em 2005 foram lançados 279 novos produtos, ou cerca de um a cada dia útil, em média. Com um portfólio que ostenta mais de seis mil itens, o perfil inovador possibilita o estabelecimento da liderança absoluta no mercado brasileiro e reflete-se em outros países da América do Sul.

\subsection{Randon}

A Randon é uma holding mista do setor de auto-indústria, líder de um conjunto de oito empresas operacionais nas áreas de implementos rodoviários, ferroviários, veículos especiais, autopeças, sistemas automotivos e serviços. Seu potencial inovador está voltado a novos produtos e possui cerca de 300 profissionais dedicados à pesquisa e ao desenvolvimento.

Com sua sede em Caxias do Sul, a empresa está presente em 13 países e possui participação expressiva no mercado norte-americano, graças ao seu investimento na modernização de seus processos.

Em 2006, a Randon obteve um faturamento de US $\$ 1,141$ bilhão, dos quais US $\$ 116,8$ milhões resultaram de suas operações do exterior. Devido ao crescimento dos setores de transportes e da necessidade de soluções inovadoras nos seus diversos segmentos, a Randon mostra-se muito bem posicionada para enfrentar os desafios da expansão internacional.

A sua atuação em diversos continentes, demonstra que sua forte ênfase na inovação tem apresentado resultados muito satisfatórios e que motivam novos investimentos em atividades inovadoras como estratégia que suporte o avanço para novos mercados estrangeiros. 


\subsection{Braskem}

Empresa do setor petroquímico que, em 2006, obteve um faturamento de US $\$ 5,388$ bilhões, dos quais US $\$ 1,394$ bilhão resultou de vendas internacionais. A organização emprega mais de 3.100 funcionários no Brasil e está presente em outros quatro países.

A Braskem atua na produção de resinas termoplásticas que são utilizadas pelas empresas que fabricam produtos a partir dos plásticos, como, por exemplo, peças para o setor automotivo, brinquedos, construção civil e utilidades domésticas, entre outros. Dessa forma, a principal matéria-prima utilizada pela Braskem é a nafta, que resulta do refino do petróleo.

A empresa é fortemente orientada para a inovação e conta com mais de uma centena de pesquisadores, distribuídos em onze laboratórios, e seis plantas-piloto que desempenham atividades de desenvolvimento e aperfeiçoamento de novos produtos e processos.

Visto que seus clientes são basicamente clientes corporativos, a capacidade de inovação da Braskem contribui significativamente para a cadeia de valor deles, proporcionando os insumos necessários à fabricação dos produtos que são consumidos e utilizados globalmente. Devido à atuação geograficamente dispersa dos seus clientes, a Braskem necessita inovar constantemente em produto e em processo para provê-los com soluções que viabilizem a produção customizada dos produtos plásticos destinados aos usuários finais.

\subsection{Natura}

Empresa do setor de bens de consumo que atua na área de cosméticos, cujo sistema de vendas e distribuição está baseado na ação das consultoras, que utilizam catálogos para oferecer produtos a seus clientes. Dispondo de mais de 500.000 consultoras no Brasil, e com 1.294 funcionários, em 2006, a Natura obteve um faturamento de US\$3,755 bilhões, dos quais US\$133,6 milhões resultaram de vendas estrangeiras.

A Natura é uma organização que estuda em profundidade a biodiversidade brasileira para a criação de produtos que promovam o "bem estar bem". Apesar da forte posição competitiva que a empresa sustenta no Brasil, ela concorre com outras empresas de cosméticos que atuam em âmbito global, dentre as quais se destacam a Avon e a L'oreal. O setor de cosméticos abrange as empresas que atuam nos negócios relacionados à beleza, contudo, muitas delas também se inserem nos setores de higiene pessoal e perfumaria, o que torna o ambiente mais dinâmico e a competição mais intensa.

A Natura iniciou sua internacionalização em 1982, direcionando sua expansão para a América Latina. Posteriormente avançou para a Europa e, atualmente, além de sua sede no Brasil, na cidade de Cajamar, a empresa está presente em outros sete países. Focada especialmente na inovação de produto, a Natura desenvolve um produto ou uma melhoria nova a cada dois ou três dias. Essa orientação inovadora da empresa possibilita a criação e a sustentação de linhas amplas de produtos. Dessa forma, os catálogos da empresa sempre possuem lançamentos, o que viabiliza o contato próximo das consultoras com suas clientes. Portanto, a postura inovadora da empresa suporta seu processo de internacionalização à medida que ela consegue replicar seu modelo de negócios nos mercados estrangeiros alvo, ampliando sua base de consultoras e, conseqüentemente, sua base de clientes. 


\section{Considerações finais}

Este trabalho foi desenvolvido com o objetivo de verificar a existência de uma relação entre o grau de internacionalização e a prática da inovação tecnológica nas empresas multinacionais brasileiras. Com base nas empresas analisadas, observou-se que a inovação tecnológica contribui fortemente para o seu processo de internacionalização. Especificamente, abordaram-se as inovações de produto e de processo e verificou-se que a criação de produtos ou processos ou o aprimoramento de produtos ou processos existentes viabiliza o atendimento das necessidades dos mercados estrangeiros locais em que as empresas pesquisadas competem.

Os casos analisados são de empresas de setores distintos, que, provavelmente, possuem diferentes trajetórias de internacionalização. Algumas empresas focam na inovação de produto, como é o caso da Marcopolo, da Weg, da Embraer, da Tigre, da Randon e da Natura. A análise individual das empresas reforçou a idéia inicial de que aquelas que concentram seus esforços nesse tipo de inovação tecnológica apresentam maior necessidade de criação de ofertas diferenciadas para atender a seus mercados, sejam eles consumidores finais, como no caso da Natura, sejam industriais, como as demais. Essas medidas asseguram a fidelidade dos clientes sensíveis aos produtos.

Outras empresas enfatizam a inovação de processo, como é o caso da Petrobras, da Sabó e da Braskem. Observou-se que, exceto pela Sabó, tratam-se de empresas do setor de petróleo, química e petroquímica, cujo apelo para a descoberta de tecnologias que propiciem formas mais eficientes de extração é um fator-chave de sucesso para manutenção de seu diferencial competitivo.

Em ambos os grupos, notou-se que a prática da inovação tecnológica objetiva fornecer o suporte necessário à implementação de suas estratégias. Observa-se, ainda, que todas as empresas tidas como mais inovadoras possuem mais de 18 anos de atuação em mercados estrangeiros. Dessa forma, destaca-se que a inovação, apesar de incorporar a incerteza, possui o propósito claro de elevar a competitividade organizacional e, conseqüentemente, viabilizar o crescimento empresarial. Entretanto, notou-se também que quanto maior for o comprometimento da empresa com os mercados estrangeiros, maior poderá ser a contribuição da inovação para a competitividade organizacional. Provavelmente isso ocorra em razão de a trajetória de internacionalização das empresas estudadas ter iniciado com modos de entrada menos arriscados, como a exportação, e somente após muitos esforços e comprometimentos tais organizações estabeleceram subsidiárias de sua propriedade. Além disso, o conhecimento local gera adaptações e, por conseqüência, aprendizado, o qual é revertido para o mercado por meio das inovações.

Pesquisas adicionais podem ser conduzidas posteriormente no sentido de verificar a trajetória do processo de internacionalização de cada uma dessas empresas. Espera-se que esta pesquisa traga alguma contribuição para os estudos de internacionalização de empresas brasileiras. 


\section{Referências}

ALMEIDA, A.; CRETOIU, S. L. Internacionalização de empresas: a experiência brasileira e o contexto latinoamericano. Revista Dom, n. 5, p. 8-16, 2008.

ARRUDA, M.; VERMULM, R.; HOLLANDA, S. Inovação tecnológica no Brasil: a indústria em busca da competitividade global. São Paulo: ANPEI, 2006.

BILKEY, W. J. An attempted integration of literature on the export behavior of firms. Journal of International Business Studies, v. 9, n. 1, p. 33-46, 1978.

BCG. Boston Consulting Group. Disponível em: <http://www.bcg.com>. 2008. Acesso em: 19 ago. 2008.

BUSINESSWEEK. Disponível em: < http:// www.businessweek.com>. 2007. Acesso em: 06 jun. 2008.

CAVUSGIL, S.T.Ontheinternationalization process of firms. European Research, v. 8, n. 6, p. 273-281, 1980.

CLARK, C.; WHEELWRIGHT, S. Creating project plans to focus product development. Harvard Business Review, p.70-82, mar./abr. 1992.

CYERT, R. D.; MARCH, J. G. A behavioral theory of the firm. Englewood Cliffs, NJ: Prentice Hall, 1963.

DOSI, G. Technological paradigms and technological trajectories: a suggested interpretation of the determinants and directions of technological change. Research Policy, v. 11, n.3, p. 147-162, 1988.
DUNNING, J. H. The contribution of Edith Penrose to international business scholarship. Management International Review, v. 43, n. 1, p. 3-19, 2003.

. The eclectic (OLI) paradigm of international production: past, present and future. International Journal of the Economics of Busines, v. 8, n. 2, p. 173190, 2001.

. The theory of international production. The international Trade Journal, v. 3, n. 1, p. 21-26, outono de 1988.

- Toward a eclectic theory of international production: Some empirical tests. Journal of International Business Studies, p. 9-31, spring/summer 1980.

- Trade, location of economic activity and the multinational enterprise: a serch for a eclectic approach. In: OHLIN, B.; HESSELBORN, P. O.; WIJKMAN, P. M. (Eds.). The international allocation of economics activity. Londres: Macmillan, 1977. p. 395-418.

EISENHARDT, K. M. Building theories from case study research. Academy of Management Review, v. 14, n. 4, p. 532550, 1989.

FINEP. Financiadora de Estudos e Projetos do Ministério da Ciência e Tecnologia. Brasil inovador: O desafio empreendedor - 40 histórias de sucesso de empresas que investem em inovação. Brasília: Expressão, 2006.

GOODE, W. J.; HATT, P. K. Métodos em pesquisa social. São Paulo: Companhia Editora Nacional, 1979. 
HITT,M.A.; IRELAND, R. D.; HOSKISSON, R. E. Administração estratégica. São Paulo: Thomson, 2002.

IBGE. Instituto Brasileiro de Geografia e Estatística. Pesquisa industrial de inovação tecnológica 2003 - Pintec. Rio de Janeiro, 2005.

JOHANSON, J.; MATTSSON, L. G .The mechanism of internationalization.

International Marketing Review, v. 7, n. 4, p. 11-24, 1990. . Internationalization in industrial systems: a network approach. In: HOOD, N.; VAHLNE, J-E (Eds.).

Strategies in global competition. Londres: Croom Helm, 1988.

JOHANSON, J.; VAHLNE, J-E. The internationalization process of the firm: a model of knowledge development and increasing foreign market commitments. Journal of International Business Studies, v. 8, n. 1, p. 23-32, 1977.

KHANNA, T.; PALEPU, K. G; SINHA, J. Strategies that fit emerging markets. Harvard Business Review, p. 63-74, jun. 2005.

OCDE. Organização para Cooperação Econômica e Desenvolvimento Departamento Estatístico da Comunidade Européia. Manual de Oslo: propostas de diretrizes para coleta e interpretação de dados sobre inovação tecnológica. 3. ed. Rio de Janeiro: FINEP, 2005.

PORTER, M. E. Estratégia competitiva: técnicas para análise de indústrias e da concorrência. 7. ed. Rio de Janeiro: Campus, 1986.

PRAHALAD, C. K. A riqueza na base da pirâmide: como erradicar a pobreza com o lucro. Porto Alegre: Bookman, 2005.
ROOT, F. R. Entry strategies for international markets. Lexington: Lexington Books, 1987.

SELLTIZ, C. et al. Métodos de pesquisa nas relações sociais. São Paulo: Pedagógica e Universidade de São Paulo, 1974.

SEVERINO, A. J. Metodologia do trabalho científico. São Paulo: Cortez, 2008.

TEIGLAND, R.; FEY, C. F.; BIRKINSHAW, J. Knowledge dissemination in global R\&D operations. Management International Review, v. 40, n. 1, p. 49-77, 2000.

TREACY, M.; WIESERMA, F. A disciplina dos líderes de mercado: escolha seus clientes, direcione seu foco, domine seu mercado. Rio de Janeiro: Rocco, 1995.

VAN DE VEN, A. H.; ANGLE, L.; POOLE, $M$. S. Research on the management of innovation: the Minnesota studies. New York: Harper\& Row, 1989.

VERNON, R. International investment in the product cycle. Quarterly Journal of Economics, v. 80, n. 2, p. 199-207, 1966.

WEBSTER, F. E. The changing role of marketing in the corporation. Journal of Marketing, v. 56, p. 1-17, 1992.

YIN, R. Case study research. London: Sage, 1994.

YIP, G. S. Global strategy in a world of nations? Havard Business

Review, p.29-41, 1989.

. Globalização: como enfrentar

os desafios da competitividade mundial. São Paulo: Senac, 1996. 